\title{
Study on simulation mechanics and fatigue performance of steel bridge deck rigid flexible composite pavement
}

\author{
Li Yinshan ${ }^{1,2}$, Liu Linlin ${ }^{1,2,}$, Li Tianyu $^{3}$, Guo Ruyong ${ }^{3}$, Wu Chunying ${ }^{1,2}$ \\ 1.JSTI Group, Nanjing 211112, China; \\ 2.National Engineering Laboratory for New Road Materials, Nanjing, Jiangsu 211112, China; \\ 3.Hohai University, Nanjing, Jiangsu 210098, China
}

\begin{abstract}
Aiming at the fatigue cracking of steel bridge deck pavement and the shortage of river sand resources, a sea sand RPC pavement scheme was proposed. Taking Quanhe steel box girder bridge as the research background, the simulation model was established by using ANSYS finite element software, and the mechanical simulation analysis of the steel bridge deck sea sand RPC-asphalt pavement composite structure was carried out to determine the most unfavorable load position. A three-point fatigue test was carried out to study the fatigue performance of the structure specimen, and a comparative analysis was made with the river sand RPC- asphalt surface composite pavement structure. The results show that the maximum tensile stress and strain of RPC-asphalt pavement appear in the upper middle span of U-shaped stiffener of steel box girder, which are $0.5241 \mathrm{MPa}$ and $98.2 \mu \varepsilon$, respectively, and the surface of the pavement in this area is prone to crack. The RPC-asphalt surface composite pavement structure has not been damaged after 2 million times of fatigue tests, and has not been damaged after 1 million times of fatigue loading after secondary loading, which indicates that it has better fatigue performance.
\end{abstract}

\section{Introduction}

Asphalt mixture is often used in steel bridge pavement. With the increase of traffic volume and heavy load phenomenon, fatigue cracking disease often occurs in steel bridge pavement. In recent years, although researchers have done a lot of research on fatigue performance of steel bridge pavement, it is still difficult to eliminate the disease without achieving a fundamental breakthrough.

The rigid flexible composite pavement structure of "steel plate + cement concrete + asphalt pavement" is based on the concept of material gradient design to increase the overall stiffness of pavement system, change the stress state of bridge deck system, and inhibit the fatigue cracking of pavement. At present, most rigid materials are steel fiber reinforced concrete, lightweight concrete and other high-performance concrete. However, through the investigation, it is found that in the engineering application of steel fiber reinforced concrete, the pavement also has surface cracking and interlayer delamination and other diseases, and the long-term fatigue performance needs to be further verified ${ }^{[1-3]}$. The surface fatigue cracking of the steel deck pavement is mainly caused by the excessive tensile stress of the pavement. Moreover, the most unfavorable position in the mechanical calculation of steel bridge deck often does not conform to the actual situation. Therefore, it is necessary to analyze the tensile stress of high performance concrete asphalt pavement structure of steel bridge deck to find out the most unfavorable position and provide parameters for fatigue test.

In addition, river sand is an indispensable component aggregate of cement concrete, and the demand for river sand has increased sharply. However, due to improper and excessive exploitation, river sand resources are increasingly scarce, the price of river sand has doubled, and the engineering cost has increased. It is necessary to seek materials that can replace river sand. China is rich in sea sand resources and the total amount of sea sand resources is about $68 \times 10^{10} \mathrm{~m}^{3}$. So the use of sea sand to prepare cement concrete is an innovative idea, and its application in steel bridge deck pavement can solve the problem of lack of river sand, and is conducive to energy conservation and ecological environment protection. However, how to use local materials and rich sea sand resources for infrastructure construction, how the durability of the prepared cement concrete, and whether it is suitable for steel bridge deck pavement, is a subject worthy of study.

In view of this, this study used sea sand instead of river sand to prepare Reactive powder concrete (RPC) and used it in steel bridge pavement layer. Based on practical requirements and in view of fatigue crack disease of pavement layer, the simulation mechanical analysis of RPC-asphalt pavement composite structure was first

*Corresponding author's e-mail: 111@jsti.com 
carried out. Taking the tensile stress or strain as the control index, the most unfavorable position was found. Based on this, three-point fatigue test was carried out to verify the fatigue performance of the composite pavement structure with RPC of sea sand and asphalt surface, and the comparison analysis was made with RPC of river sand. The research results provide technical reference for the popularization and application of sea sand in rigid flexible composite pavement of steel bridge deck.

\section{Material}

\subsection{SMA-13 Asphalt Mixtures}

The asphalt binding material adopts high viscosity and high elastic modified asphalt. The residual stability of SMA-13 asphalt mixture is $91 \%$, the freeze-thaw splitting strength ratio is $88 \%$, the dynamic stability is 11021 times $/ \mathrm{mm}$, and the bending failure strain is $4121 \mu \varepsilon$, all of which meet the specification requirements of "Technical Specification for Highway Asphalt Pavement Construction" (JTG F40-2004).

\subsection{Waterproof adhesive layer material}

Waterproof binder material using reaction type binder, the elongation of $10 \mathrm{~mm}$, fracture elongation of $92 \%$, bond strength of $1.6 \mathrm{MPa}\left(25^{\circ} \mathrm{C}\right)$, shear strength of $1.5 \mathrm{MPa}$ $\left(25^{\circ} \mathrm{C}\right)$, at $160 \pm 2^{\circ} \mathrm{C}$ when no flow and sliding phenomenon, at $-25^{\circ} \mathrm{C} \pm 2^{\circ} \mathrm{C}$ when no crack.

\subsection{Reactive Powder Concrete (RPC)}

RPC is composed of cement, fly ash, limestone powder, silica fume, high efficiency water reducer, steel fiber and so on. The test uses P.O 42.5 grade cement, the average particle size of silica fume is $0.1 \sim 0.2 \mu \mathrm{m}$, the fineness of I grade fly ash is $10 \%$, the solid content of polycarboxylic acid high performance water reducer is $40 \%$, and the water reduction rate is $35 \%$. The steel fiber length is 13 $\mathrm{mm}$, the fiber diameter is $0.2 \mathrm{~mm}$, the fiber aspect ratio is 65 , and the tensile strength is more than $2850 \mathrm{MPa}$. The fineness modulus of sea sand is 2.6 , the chloride ion content is $0.06 \%$, and the fineness modulus of river sand is 2.5. Seawater is the solution prepared for the net sale of sea salt (chloride ion concentration of $3.5 \%$ ), water for drinking tap water. RPC of sea sand has a compressive strength of $124 \mathrm{MPa}$ and a flexural strength of $17.1 \mathrm{MPa}$. $\mathrm{RPC}$ of river sand has a compressive strength of $131 \mathrm{MPa}$ and a flexural strength of $20.1 \mathrm{MPa}$. The mechanical properties of the prepared RPC fully meet the requirements of Reactive Powder Concrete (GB/T 313872015) for RPC120 grade.

\section{Mechanical analysis of composite pavement structure}

Taking the cable-stayed steel bridge of Quanhe Bridge as the background, the bridge deck thickness is $14 \mathrm{~mm}$, the thickness of longitudinal and transverse diaphragms is $14 \mathrm{~mm}$, the spacing of transverse diaphragms is $3 \mathrm{~m}$, the thickness of roof ribs is $8 \mathrm{~mm}$, the opening width of roof ribs is $300 \mathrm{~mm}$, the bottom width is $170 \mathrm{~mm}$, the rib height is $280 \mathrm{~mm}$, and the spacing of ribs is $580 \mathrm{~mm}$. The partial beam section was taken, and the finite element model was established by ANSYS software to analyze the mechanical performance of the installation system. The pavement scheme was: steel panel $+6 \mathrm{~cm}$ thick RPC $+4 \mathrm{~cm}$ thick SMA-13 asphalt mixture.

\subsection{Finite element model}

The finite element model of steel box girder consists of 4 U-shaped stiffeners, 4 diaphragms and 1 longitudinal diaphragms, with a longitudinal span of 3 spans (1 span between the two diaphragms) and a total length of $9 \mathrm{~m}$. The model structure pavement is equipped with Solid45 solid units on the upper layer, and Shell63 shell units are used for steel bridge decks, longitudinal and horizontal diaphragmboards and U-shaped stiffeners ${ }^{[4]}$.

\subsection{Boundary conditions}

The basic assumptions are as follows :(1) the deck system of a steel bridge is a completely continuous isotropic elastomer; (2) The contact between the pavement layer and the steel panel is completely continuous, without considering the relative slip; (3) Regardless of the influence of structure weight; (4) The bottom of the longitudinal and horizontal partitions is consolidated, and there is no horizontal displacement at the edges of the transverse and parallel Bridges ${ }^{[5]}$.

\subsection{Material parameters}

The elastic modulus of steel, RPC and SMA-13 asphalt mixture is $2.1 \times 10^{5} \mathrm{MPa}, 4.0 \times 10^{4} \mathrm{MPa}$ and $1.5 \times 10^{3} \mathrm{MPa}$, respectively. The Poisson's ratios of steel, RPC and SMA13 asphalt mixtures are $0.33,0.3$ and 0.3 , respectively. ANSYS finite element software was used to establish a finite element model.

\subsection{Load layout}

According to literature [6], the load was $0.758 \mathrm{MPa}$. When analyzing the position of the most adverse load on the transverse bridge, the wheel load is divided into five situations as shown in Fig. 1. When analyzing the most unfavorable load positions in the longitudinal bridge direction, the load positions are respectively the top of the diaphragm, the $1 / 4$ position of the two diaphragm plates, and the mid-span of the two diaphragm plates, as shown in Fig. 2. 


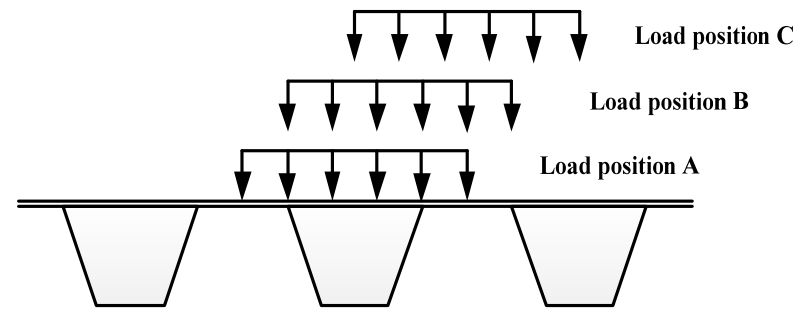

Fig.1 Schematic diagram of lateral load arrangement

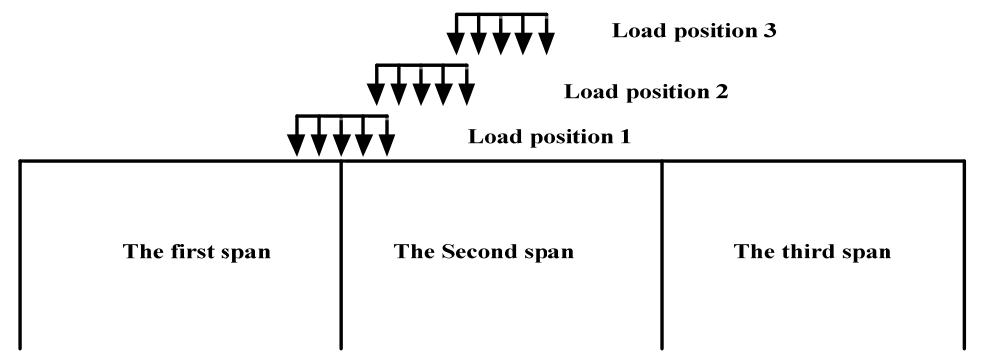

Fig.2 Schematic diagram of longitudinal load arrangement

The load applied in this study consists of 3 transverse bridge positions and 3 longitudinal bridge positions, which constitute a total of 9 load positions numbered A1, A2, A3, B1, B2, B3, C1, C2 and C3, that is, the first letter refers to the wheel load acting in the transverse direction, and the second number refers to the wheel load acting in the longitudinal direction ${ }^{[7]}$.

\subsection{Material parameters}

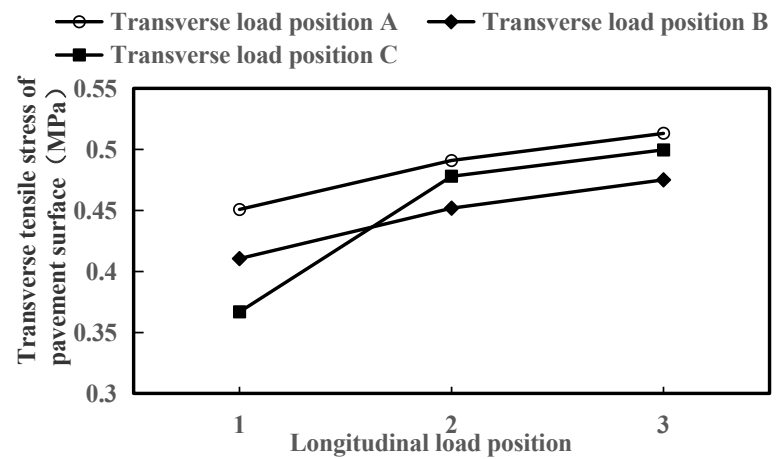

Fig.3 Variation law of longitudinal tensile stress with position of longitudinal load

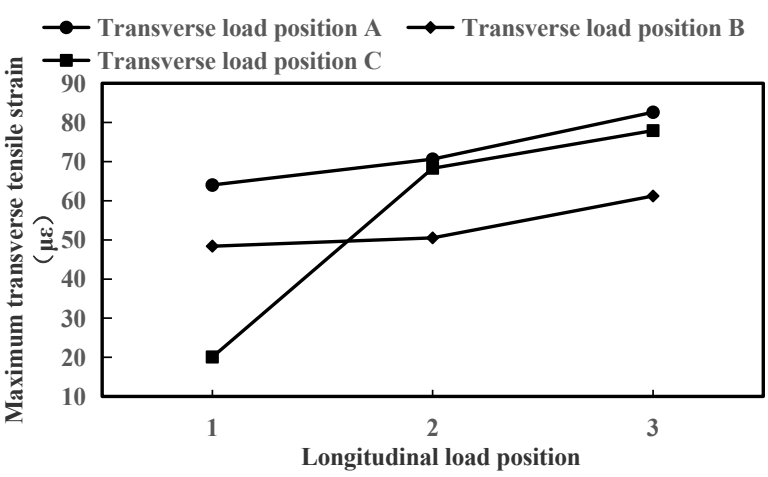

Fig.5 Variation law of longitudinal tensile strain with position of longitudinal load
The maximum transverse and longitudinal tensile stress on the surface of steel bridge deck pavement is the main reason for cracking on the surface of steel bridge deck pavement in the transverse and longitudinal directions. Therefore, the influence of wheel load position on the tensile stress on the surface of steel bridge deck pavement is mainly considered. Finite element mechanical simulation calculation is conducted for 9 load positions, and the results are shown in Figure 3 and Figure 4.

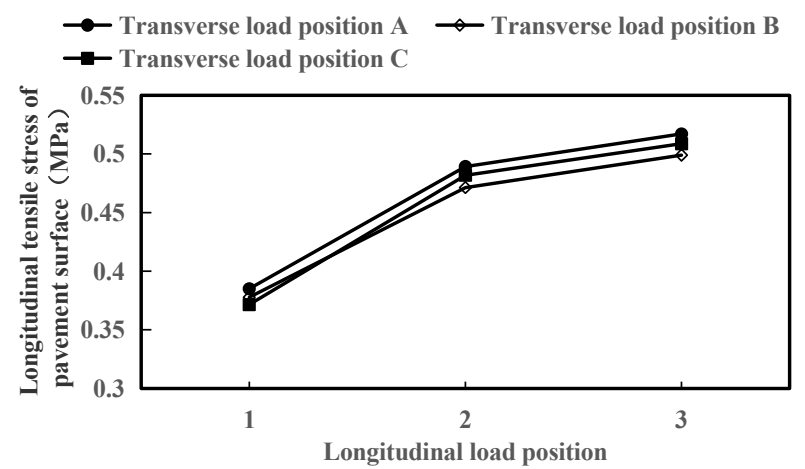

Fig.4 Variation law of transverse tensile stress with position of longitudinal load

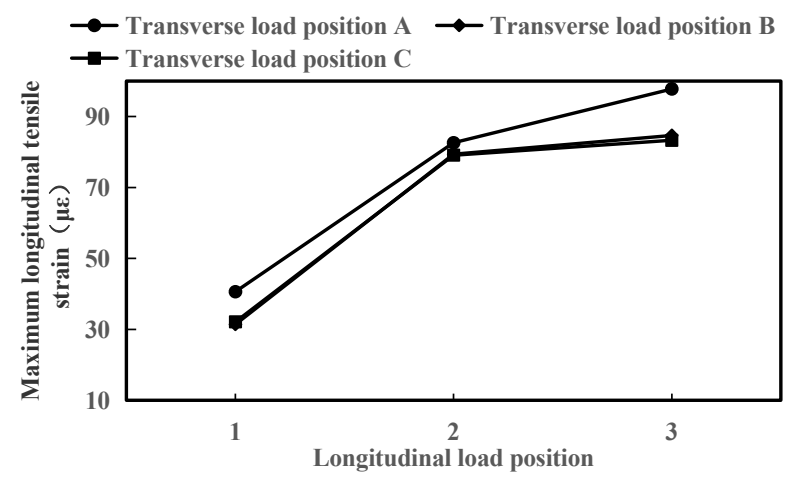

Fig.6 Variation law of transverse tensile strain with position of longitudinal load 
According to the analysis results in Fig. 4 and Fig. 5, it can be seen that:(1) As the wheel load moves from the upper part of the diaphragm to the middle span in the longitudinal direction, the transverse tensile stress and longitudinal tensile stress on the pavement surface of the transverse load positions A, B, C, D and E show A trend of gradual increase, and the maximum tensile stress appears in the middle span. (2) Under the same longitudinal load position, the maximum transverse tensile stress appears at the lateral load position $\mathrm{A}$, and the result is $0.5241 \mathrm{MPa}$. Therefore, when the maximum tensile stress of the pavement is taken as the fatigue crack control index, the most adverse load position in the transverse bridge is $\mathrm{A}$, and the load position in the longitudinal bridge is 3 .

According to the analysis results in Fig. 5 and Fig. 6, the changes of the maximum transverse tensile strain and the maximum longitudinal tensile strain on the surface of the pavement layer are consistent with the changes of the maximum transverse tensile stress and the maximum longitudinal tensile stress on the surface of the pavement layer under various load positions. The most unfavorable load position of the transverse bridge is $\mathrm{A}$, and the longitudinal bridge acts upward on the mid-span position between the two diaphragm plates. The maximum transverse tensile strain value of the pavement surface is $83.7 \mu \varepsilon$, and the maximum longitudinal tensile strain value is $98.2 \mu \varepsilon$.

\section{Analysis of fatigue performance of composite pavement structure}

Based on section 2 mechanics finite element simulation analysis, the most unfavorable load positions of composite pavement structure the most unfavorable for upper tensile stress characteristics, therefore, in order to simulate the steel bridge deck of composite pavement structure the most unfavorable stress characteristic, forming composite beam structure, above the lower tension compression way of composite beam fatigue test, Test the overall anti- fatigue failure ability of RPC-asphalt pavement composite layer ${ }^{[8]}$.

\subsection{Test methods}

The fatigue test of composite beam was carried out according to the fatigue test method of three-point loading composite beam in Appendix E of literature [9]. The size of the specimen is $380 \mathrm{~mm} \times 100 \mathrm{~mm} \times 100 \mathrm{~mm}$, the thickness of the lower layer of the pavement is $60 \mathrm{~mm}$, and the thickness of the upper layer of the pavement is $40 \mathrm{~mm}$. The test temperature is $20^{\circ} \mathrm{C}$, the stress control mode is adopted, the load is sinusoidal wave, and the loading frequency is $10 \mathrm{~Hz}$. Based on the principle of stress equivalence, the maximum tensile stress obtained by mechanical simulation analysis is converted as the loading force of fatigue test.Figure 7 is the loading diagram of three-point fatigue test.

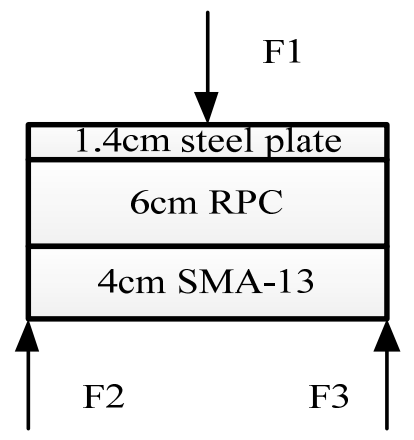

Fig.7 Schematic diagram of composite beam loading test

\subsection{Analysis of test results}

According to the test conditions in Section 3, the UTM100 fatigue testing machine is used for the test, and the system automatically collects the test data of displacement, stress, strain and so on. The fatigue comparison test results are shown in Table 1.

Table 1. Fatigue test results of composite components

\begin{tabular}{ccccc}
\hline & \multicolumn{2}{c}{ First time loading } & \multicolumn{2}{c}{ Secondary load } \\
\cline { 2 - 5 } Plan & Fatigue load/kN & $\begin{array}{c}\text { Number of } \\
\text { fatigue(Ten } \\
\text { thousand times) }\end{array}$ & Fatigue load/kN & $\begin{array}{c}\text { Number of } \\
\text { fatigue(Ten } \\
\text { thousand times) }\end{array}$ \\
\hline River sand RPC+SMA-13 & 5 & 200 & 10 & 100 \\
Sea sand RPC+SMA-13 & 5 & 200 & 10 & 100 \\
\hline
\end{tabular}

After 2 million times of fatigue tests under the initial load of $5 \mathrm{kN}$, no damage occurred to the RPC-asphalt surface layer of sea sand and the RPC-asphalt surface composite beam of river sand. Then, the second load was applied with $10 \mathrm{kN}$, and no damage occurred when the fatigue load reached 1 million times, and then the test was stopped.

From the whole test process, the load-deflection test curve obtained after the fatigue test of the composite beam showed that the bending stiffness of the composite beam did not attenuated. When the fatigue loading force is higher than the initial loading force, the rigid flexible composite structure does not appear damage, so it can be seen that the composite pavement structure prepared by sea sand RPC and river sand RPC has better fatigue performance, which can effectively prolong the service life of steel bridge deck pavement layer.

\section{Conclusion}

Taking Quanhe Bridge as the background, this study carried out mechanical simulation analysis and experimental research on the steel bridge deck RPCasphalt pavement composite structure with sea sand, and 
made a comparative analysis with the river sand RPCasphalt pavement composite structure. The main conclusions are as follows:

(1)Simulation analysis of RPC- asphalt surface composite pavement structure of sea sand. Results show that the maximum tensile stress in pavement as A fatigue crack control index, the spring river bridge steel bridge deck of composite pavement structure is the bridge to the most unfavorable load position load position A, ele vated load location to be 3 , the maximum tensile stress is 0.5241 $\mathrm{MPa}$, the maximum tensile strain of $98.2 \mathrm{mu}$ epsilon, and the region is prone to cracking, form of top-down. Therefore, it is necessary to meet the requirements of this mechanical index when designing pavement materials.

(2)Fatigue tests were carried out on RPC- asphalt surface composite beams with sea sand and RPC- asphalt surface composite beams with river sand. The fatigue test results show that the composite beam has not been damaged after 2 million times of fatigue tests under the fatigue load specified in the code, and has not been damaged after 1 million times of fatigue loading when the secondary loading force is higher than the fatigue load specified in the code.

(3)Steel bridge deck RPC-asphalt surface composite pavement structure has better fatigue performance, the test results verify the feasibility of sea sand RPC on steel bridge deck pavement.

\section{Acknowledgments}

Internal research and development project of JSTI Group, Project Name: Structural Performance Research of Rigidflexible Composite Pavement with Steel Deck, Project No. 1988062.

\section{References}

1. Lee penang Qian. Analysis of main diseases and prevention measures of steel bridge deck pavement [J]. West China Transportation Science and Technology, 2014(3):51-56.

2. QIAN Jin. Design Method of Steel Deck Pavement of Long-span Bridges [D]. Hubei University of Technology, 2011.

3. Feng Xiaotian. Analysis of Mechanical Properties of High Strength and High Ductile Concrete Steel Bridge Deck Pavement System [D]. Hunan University, 2012.

4. LI Ye. Influence of Cracks on Mechanical Properties of Steel Bridge Deck Pavement [J]. Journal of Jiamusi University (Natural Science Edition), 2015(2).

5. Li Jia, Feng Xiaotian, Shao Xudong, et al. Journal of Hunan University (Natural Science Edition), 2012, 39(12):7-12. (in Chinese)

6. Ministry of Transport. General Code for Design of Highway Bridges and Culverts: JTG D60-2015[S], Beijing: People's Communications Press,2015.
7. Chen Sichun. Research on Mechanical Properties of Asphuminous Concrete Pavement with Steel Reinforced Beam [D]. Fuzhou University, 2010.

8. Li Xuelian, Zhou Zhigang. Research on New Composite Pavement Structure of Orthotropic Steel Deck [J]. Highway Traffic Science and Technology, 2010.

9. Ministry of Transport. Technical Code for Design and Construction of Highway Steel Bridge Deck Pavement: JTG/T3364-02 -- 2019[S], Beijing: People's Communications Press,2019. 